CORRECTION

\title{
Correction: The prefrontal cortex, pathological anxiety, and anxiety disorders
}

Margaux M. Kenwood, Ned H. Kalin and Helen Barbas

(c) The Author(s), under exclusive licence to American College of Neuropsychopharmacology 2022

Neuropsychopharmacology (2022) 47:1141; https://doi.org/10.1038/s41386-021-01216-x

Correction to: Neuropsychopharmacology https://doi.org/10.1038/ s41386-021-01109-z, published online 16 August 2021
In this article reference 188 was mistakenly linked to Öngür and Price 2000. It is now corrected and linked to Chavanne and Robinson, 2021.

The original article has been corrected. 